\title{
The Baby Cooling Project of Japan to Implement Evidence-Based Neonatal Cooling
}

\author{
Osuke Iwata, ${ }^{1,2}$ Toshiki Takenouchi, ${ }^{3}$ Sachiko Iwata, ${ }^{1}$ Makoto Nabetani, ${ }^{4}$ Takeo Mukai, ${ }^{4}$ \\ Jun Shibasaki, ${ }^{5}$ Kennosuke Tsuda, ${ }^{1}$ Takuya Tokuhisa, ${ }^{6}$ Hisanori Sobajima, ${ }^{7}$ and Masanori Tamura ${ }^{7}$
}

Therapeutic hypothermia was first recommended as a standard of care by international guidelines in 2010 . However, at that time, the number of centers capable of providing standard cooling was limited even in Japan. The aim of this project was to implement a nationwide network of evidence-based cooling within 3 years. A taskforce was formed in June 2010 to undergo the primary nationwide practice survey, design of action plans, and the appraisal of interventions by involving all registered level-II/III neonatal intensive care units in Japan. Based on findings from the primary survey, aggressive action plans were introduced that focused on the formulation of clinical recommendations, facilitation of educational events, and opening of an online case registry. Findings from the follow-up survey (January 2013) were compared with the results from the primary survey (June 2010). Four workshops and three consensus meetings were held to formulate clinical recommendations, which were followed by the publication of practical textbooks, large-scale education seminars, and implementation of a case registry. A follow-up survey covering 253 units (response rate: 89.1\%) showed that cooling centers increased from 89 to 135 . Twelve prefectures had no cooling centers in 2010, whereas all 47 prefectures had at least one in 2013. In cooling centers, adherence to the standard cooling protocols and the use of servo-controlled cooling devices improved from $20.7 \%$ to $94.7 \%$ and from $79.8 \%$ to $98.5 \%$, respectively. A rapid improvement in the national provision of evidence-based cooling was achieved. International consensus guidelines coupled with domestic interventions might be effective in changing empirical approaches to evidence-based practice.

\section{Introduction}

A SERIES OF LARGE-SCALE randomized-controlled trials (RCTs) of therapeutic hypothermia (TH) consistently demonstrated the neuroprotective effect of cooling in asphyxiated newborn infants (Gluckman et al., 2005; Shankaran et al., 2005; Azzopardi et al., 2009; Jacobs et al., 2013). Follow-up studies of three RCTs suggested some benefit of TH even at early school age (Guillet et al., 2012; Shankaran et al., 2012; Azzopardi et al., 2014). TH was recommended as a standard of care for moderate to severe neonatal encephalopathy for the first time in the Consensus Statement and Treatment Recommendation on Cardio-Pulmonary Resuscitation revised in October 2010 (2010 CoSTR) (Perlman et al., 2010). Recent studies have addressed the potential benefit of cooling applied at different times, duration, and depth, or to additional groups of newborn infants (Shankaran, 2012). These were speculated to improve the neuroprotective effect of cooling and to increase the range of infants who would benefit. Simple, alternative cooling modalities have been investigated for use in low-resource settings, such as in developing countries (Robertson et al., 2008; Iwata et al., 2009; Thayyil et al., 2009), and during transportation (Kendall et al., 2010). However, thus far, abbreviated cooling strategies applied in low-resource settings have mainly been linked with trends toward increased unfavorable events (Robertson et al., 2008; Thayyil et al., 2009), suggesting that, in clinical practice, protocols used in large-scale RCTs are currently the only strategies which assure beneficial effects of $\mathrm{TH}$.

\footnotetext{
${ }^{1}$ Department of Pediatrics \& Child Health, Centre for Developmental \& Cognitive Neuroscience, Kurume University School of Medicine, Fukuoka, Japan.

${ }^{2}$ St. Mary's Hospital, Fukuoka, Japan.

${ }^{3}$ Division of Pediatric Neurology, Department of Pediatrics, Keio University School of Medicine, Tokyo, Japan.

${ }^{4}$ Division of Pediatrics, Yodogawa Christian's Hospital, Osaka, Japan.

${ }^{5}$ Division of Neonatology, Kanagawa Children's Medical Center, Kanagawa, Japan.

${ }^{6}$ Division of Neonatology, Kagoshima City Hospital, Kagoshima, Japan.

${ }^{7}$ Department of Pediatrics, Saitama Medical Center, Saitama Medical University, Kawagoe, Japan.
} 
This project aimed at implementing evidence-based cooling protocols and at developing a nationwide network of $\mathrm{TH}$ for neonatal encephalopathy in Japan within 3 years.

\section{Materials and Methods}

The protocols of the surveys and the registry were approved by the Ethics Committees of Kurume University School of Medicine and Saitama Medical University.

Foundation of a taskforce, initial survey, and action plans

In June 2010, the Japan Society of Perinatal and Neonatal Medicine, and the Clinical Guidelines Committee for Neonatal Resuscitation in Japan (Neonatal Research Network Japan, Ministry of Health, Labour and Welfare), formed a taskforce (Neonatal Hypothermia Task Force Japan) with four pediatricians (Osuke Iwata, Toshiki Takenouchi, Makoto Nabetani, and Masanori Tamura; Supplementary Table S1; Supplementary Data are available online at www.liebertpub .com/ther). To capture the distribution of neonatal intensive care units that were able to provide standard $\mathrm{TH}$ at the time, the taskforce conducted a nationwide survey in August 2010 (Survey 2010), which consisted of 45 questions asking the size and type of the unit, locally available resources, therapeutic strategy for neonatal encephalopathy, cooling protocol, supportive treatments, and follow-up programs (Iwata et al., 2012). This survey showed a significant shortage in the number of units that were capable of providing TH, as well as poor adherence to the standard TH protocol. This result forced the taskforce to form aggressive interventions, which comprised (i) formulation of clinical recommendations, (ii) implementation of evidence-based TH for clinicians, and (iii) facilitation of an online case registry (Fig. 1).

\section{Formulation of domestic clinical recommendations}

Four large-scale workshops were scheduled between November 2010 and July 2011 in conjunction with major domestic scientific meetings in perinatal medicine. The workshops aimed at (i) introducing the concept of revised international recommendations for neonatal resuscitation and TH (Perlman et al., 2010), (ii) sharing the domestic issues in Japan highlighted from the Survey 2010 (Iwata et al., 2012), (iii) presenting a draft of clinical recommendations of $\mathrm{TH}$ (drafted by the taskforce members by summarizing the entry criteria and protocols for large-scale RCTs), and (iv) calling for public and expert opinion. Three consensus meetings were held to form an expert committee (Supplementary Table S1). Domestic experts of neonatal intensive care, child neurology, and clinical investigations were invited from members of the council board of domestic medical societies in pediatrics and perinatal medicine. The committee discussed the public and expert comments obtained at or after the workshops. The committee also delineated specific domestic backgrounds in Japan, which may require consideration in applying clinical recommendations in Western countries. The draft of the clinical recommendations was revised by the committee members and was presented for approval at the workshop in July 2011.

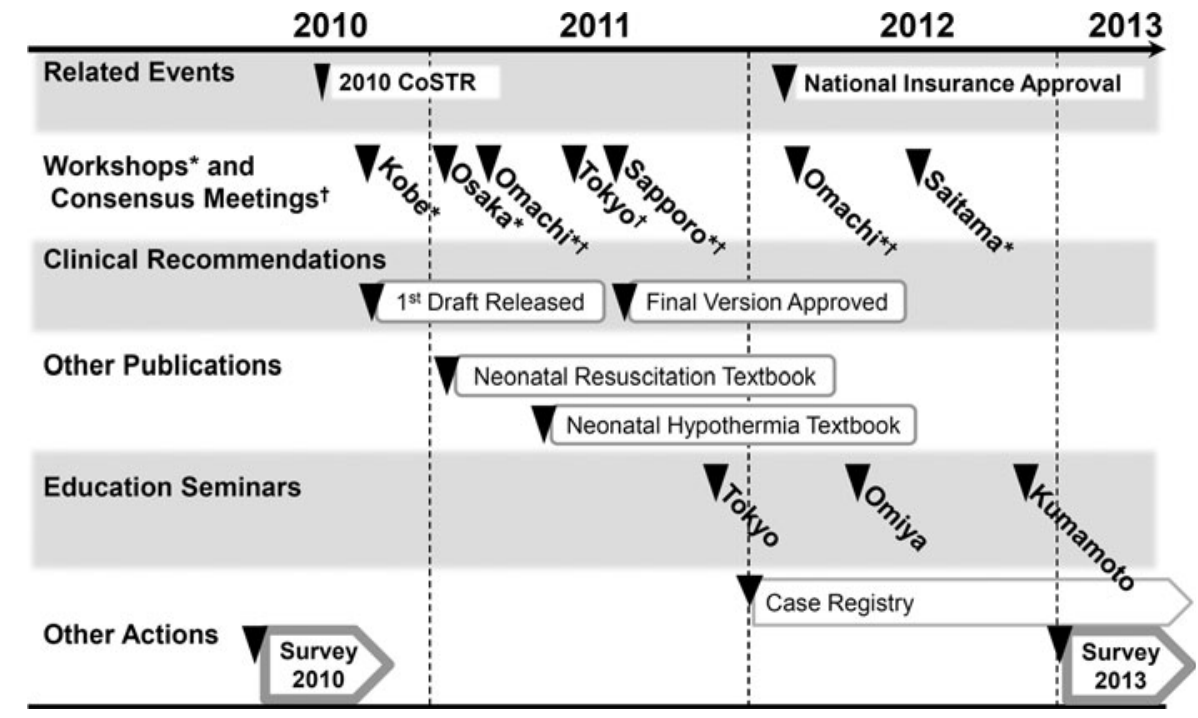

FIG. 1. Timeline of action plans by the Neonatal Hypothermia Task Force Japan. The Neonatal Hypothermia Task Force was created in June 2010 to implement evidence-based cooling in newborn infants in Japan. Action plans included formulation of clinical recommendations based on a series of workshops and consensus meetings, facilitating education seminars, dissemination of practical textbooks and opening of an online case registry for cooled infants. Two separate surveys were conducted before and after these intensive interventions. Most workshops, consensus meetings and educational seminars were held in conjunction with annual meetings for the Japan Society for Premature and Newborn Medicine (November 2010, Kobe; November 2011, Tokyo; November 2012, Kumamoto), Convention for Japanese Perinatal Centers (January 2011, Osaka), the Neonatal Respiratory Care and Monitoring Forum (February 2011 and 2012, Omachi), and the Japan Society of Perinatal and Neonatal Medicine (July 2011, Sapporo; July 2012, Saitama). A principal investigator of the UK TOBY Trial and the leading author of the chapter for neonatal resuscitation, $2010 \mathrm{CoSTR}$, were invited to three of these events as discussants. CoSTR, Consensus on Resuscitation Science and Treatment Recommendations. 


\section{Educational interventions}

Three educational seminars were scheduled in conjunction with major scientific meetings in perinatal medicine. These seminars targeted a wide range of medical staffs who were unfamiliar with $\mathrm{TH}$ for newborn infants. The taskforce also published a practical textbook of $\mathrm{TH}$, which illustrated the basic principles and procedures of $\mathrm{TH}$ with maximum emphasis on the relevance and importance of observing the standard cooling protocols (Tamura et al., 2010). Another practical textbook of neonatal resuscitation was published to improve the quality of neonatal resuscitation and the triage of infants who may have a clinical indication for TH (Tamura, 2010).

\section{Case registry}

To persistently monitor the practice of $\mathrm{TH}$ in newborns, an online case registry was developed. While basic survey items, such as patients' clinical background variables, severity of encephalopathy, core body temperatures, supportive treatments, adverse events, and short-term outcomes, were adopted from the UK TOBY Register (Azzopardi et al., 2012), additional items, such as the type of sedation and other neuroprotective treatments, were given to highlight domestic characteristics in Japan (Neonatal Hypothermia Task Force Japan, 2012). All of the level-II/III neonatal intensive care centers were invited to join the registry by applying for an online institutional account, with which clinical information can be submitted via the official website of the Baby Cooling Japan Registry (Neonatal Hypothermia Task Force Japan, 2012). Representatives of registered centers reported primary and secondary information within 2 months after admission and discharge of the cooled infant, respectively. We plan to convey the findings from the registry on the website of the case registry (Neonatal Hypothermia Task Force Japan, 2012) and at twice-yearly educational seminars of TH.

\section{Assessment}

To assess changes in clinical practice before and after the implementation of the program, a secondary survey was conducted in January 2013 (Survey 2013) by sending a set of questionnaires on January 1 to all 284 level-II/III neonatal intensive care units registered with the Japan Society of Perinatal and Neonatal Medicine (January, 2013). Five questionnaires about the type/size of the unit and the application of TH (addressed to all centers) and 19 extensive questionnaires about the cooling indication/protocol, adverse events, supportive treatments, and follow-up protocols (addressed to cooling centers only) were extracted from the items of the Survey 2010 (Supplementary Table S2) (Iwata et al., 2012). A reminder letter was sent on 28th January to nonresponding centers by extending the deadline from 31st January to 7th February. Results from the initial and follow-up surveys were compared using the chi-square test or Fisher's exact test.

\section{Results}

\section{Formulation of domestic clinical recommendations}

At the workshops, the critical gaps in practice of $\mathrm{TH}$ between Japan and Western countries, which were highlighted by the Survey 2010, were shared, resulting in the approval of the general concept of implementing the protocols of $\mathrm{TH}$ used in large-scale RCTs by the audience. Public/expert opinions on the draft of clinical recommendations were mainly requests to approve empirically developed/disseminated domestic cooling protocols, which had different indication criteria (e.g., 5-minute Apgar scores $\leq 6$ ), core-body temperature monitoring (e.g., nasopharyngeal), depths (e.g., $35^{\circ} \mathrm{C}$ ), durations (e.g., 98 hours), modalities (e.g., ice bags), and supportive treatments (e.g., routine use of muscle relaxants) (Iwata and Takenouchi, 2012; Iwata et al., 2012). The expert committee carefully discussed the relevance of such modifications of the standard protocols. However, no clinical evidence was found to support the equality/superiority of the modified protocols. The committee concluded that the difference in variables induced by any of these changes might alter the beneficial effect of $\mathrm{TH}$, and that the clinical protocols of large-scale RCTs should be adopted without changes. The final version of the clinical recommendations was approved by the attendees of the final workshop in July 2011, and this was then published in Japanese and English (Takenouchi et al., 2012).

\section{Educational interventions}

Practical textbooks of neonatal resuscitation and $\mathrm{TH}$ were published in January and April 2011, respectively (Tamura, 2010; Tamura et al., 2010). Three large-scale education seminars were held between November 2011 and November 2012 with attendance from 256 institutions. Further education seminars are scheduled approximately twice a year.

\section{Case registry}

The benefit and feasibility of opening an online case registry for neonatal TH were strongly supported by attendees of the workshops and consensus meetings. In January 2012, an online case registry for neonatal hypothermia was opened by initially involving 73 neonatal intensive care centers across the nation (Neonatal Hypothermia Task Force Japan, 2012). By the end of October 2013, the number of participating centers reached 145, resulting in 325 cumulative cases registered (Fig. 2). Findings of this registry will be reported elsewhere.

\section{Changes in practice in 3 years}

The Survey 2013 obtained responses from 253 level-II/III neonatal intensive care units, yielding a response rate of $89.1 \%$ (slightly higher than $83.9 \%$ in the Survey 2010). The number of cooling centers increased from 89 in the Survey 2010 (Iwata et al., 2012) (55 level-II and 34 level-III units) to 135 in the Survey 2013 (70 level-II and 65 level-III units; $p<0.05)$. In 2010, 12 of 47 prefectures had no cooling centers. However, in 2013, TH was readily available in all 47 prefectures (Table 1).

In the Survey 2013, even in the centers that had not applied $\mathrm{TH}$ at the time, 11 units were ready to provide $\mathrm{TH}$ and three units were preparing to provide $\mathrm{TH}$ in the near future. With regard to the reasons for "not cooling," a lack of human/ medical resources and clinical evidence decreased from $85.1 \%$ to $75.0 \%$ and from $18.4 \%$ to $2.6 \%$, respectively. However, a lack of cases and/or the presence of neighboring cooling centers increased from $21.1 \%$ to $41.2 \%$. In active cooling centers, adherence to the standard cooling protocols 
FIG. 2. Number of registrations and centers which registered cases. Monthly and cumulative numbers of (A) registered patients to the Baby Cooling Japan Registry and (B) neonatal intensive care centers which registered patients, showing consistent number of registrations and participating centers since the opening of the system in January 2012.

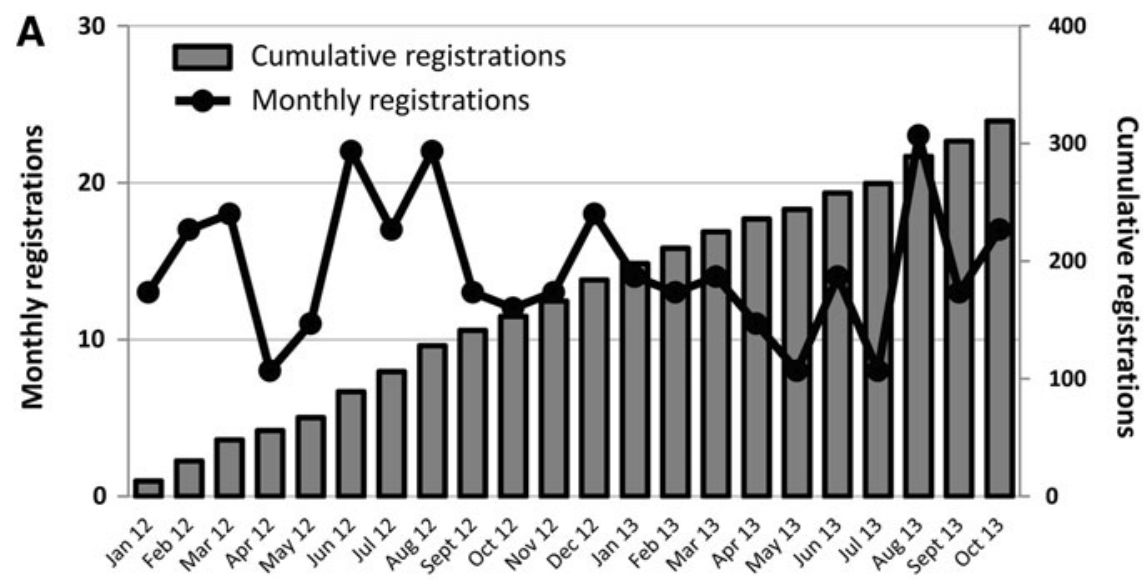

B

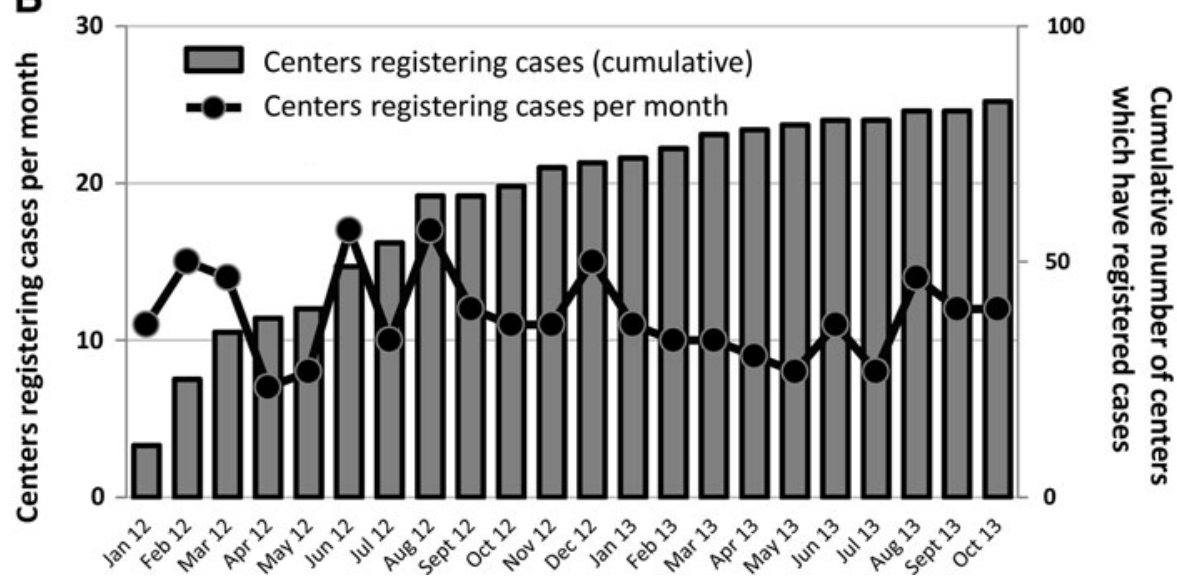

and the use of servo-controlled cooling devices significantly improved from $20.7 \%$ to $94.7 \%(p<0.001)$ and from $79.8 \%$ to $98.5 \%(p<0.001)$, respectively. The use of selective head cooling and whole body cooling changed from $88.8 \%$ to $56.1 \%$ and from $11.2 \%$ to $43.9 \%$, respectively. A total of $91.8 \%$ and $92.2 \%$ of cooled infants were followed up at least until the age of 6 years in 2010 and 2013, respectively.

\section{Discussion}

To promote evidence-based TH for neonatal encephalopathy, a series of aggressive educational events were delivered on a nationwide level since the publication of 2010 CoSTR. The program focused on the formulation of domestic clinical recommendations, education of medical staff, and facilitation of a national case registry. Subsequently, national provisions of standard $\mathrm{TH}$ were achieved within 3 years. Our findings suggest that the approval of new therapeutic options by international guidelines may benefit from simultaneous educational action plans at the domestic level.

The neuroprotective effect of $\mathrm{TH}$ has been established in encephalopathic newborn infants (Gluckman et al., 2005; Azzopardi et al., 2009; Shankaran et al., 2005). However, to assure the benefit of this treatment, standard cooling criteria and protocols should be observed until further clinical evidence confirms the advantage of newly developed regimens (Kendall et al., 2010; Thoresen, 2010). As shown by the Survey 2010 (Iwata et al., 2012), preparations for TH were unsatisfactory even in Japan. Strong trends toward empirically modified protocols for indication and temperature control were evident at the time, presumably because of a specific background in Japan that TH had clinically been applied in some neonatal intensive care units using empirically acquired protocols since the late 1990s (Iwata and Takenouchi, 2012). This urged the taskforce to perform prompt and efficient intervention to implement standard cooling protocols across the nation. An intensive program was designed to enlighten the relevance and importance of adhering to an evidence-based protocol by facilitating a series of educational events. This program targeted a wide range of clinical staff, including midwives, obstetricians, pediatricians, neonatologists, and nurses. The Survey 2013 showed that, apart from the increase in the number of cooling units, adherence to standard cooling protocols significantly improved. Even in units that still did not provide $\mathrm{TH}$, the reasons for "not cooling" shifted from a lack of evidence and human/ medical resources to a lack of cases and the presence of nearby cooling centers. Such dramatic changes might have accelerated approval of $\mathrm{TH}$ for asphyxiated newborn infants by the national health insurance agency in April 2012.

When a new therapeutic strategy is being introduced to clinical practice, priority should be placed on assurance of the safety of the treatment (Laventhal et al., 2012). However, in reality, therapies are often applied preliminarily before the accumulation of clinical evidence, where techniques are acquired using empirical approaches (Iwata and Takenouchi, 2012). 
Table 1. Change in Practice at Neonatal Intensive Care Centers That Provided Therapeutic Hypothermia in August 2010 and January 2013

\begin{tabular}{|c|c|c|c|}
\hline & $2010(\mathrm{n}=89)$ & $2013(\mathrm{n}=135)$ & $\mathrm{p}$-Values ${ }^{\mathrm{a}}$ \\
\hline Cooled infants in previous 12 months & 234 & 313 & Not tested \\
\hline $\begin{array}{l}\text { Cooling indication } \\
\text { Same with large-scale RCTs } \\
\text { Other criteria }\end{array}$ & $\begin{array}{l}18(20.7) \\
69(79.3)\end{array}$ & $\begin{array}{r}125(94.7) \\
7(5.3)\end{array}$ & $<0.001$ \\
\hline $\begin{array}{l}\text { Cooling modality } \\
\text { Whole body } \\
\text { Selective head }\end{array}$ & $\begin{array}{l}10(11.2) \\
79(88.8)\end{array}$ & $\begin{array}{l}58(43.9) \\
74(56.1)\end{array}$ & $<0.001$ \\
\hline $\begin{array}{l}\text { Cooling device used } \\
\text { Purpose-built } \mathrm{t}^{\mathrm{b}} \\
\text { Alternative }\end{array}$ & $\begin{array}{l}71(79.8) \\
18(20.2)\end{array}$ & $\begin{array}{r}129(98.5) \\
2(1.5)\end{array}$ & $<0.001$ \\
\hline $\begin{array}{l}\text { Continuous body temperature monitori } \\
\text { Yes } \\
\text { No }\end{array}$ & $\begin{array}{l}73(84.9) \\
13(15.1)\end{array}$ & $\begin{array}{c}126(95.5) \\
6(4.5)\end{array}$ & 0.026 \\
\hline $\begin{array}{l}\text { Monitoring of rectal or esophageal tem } \\
\text { Yes } \\
\text { No }\end{array}$ & $\begin{array}{l}73(82.0) \\
16(18.0)\end{array}$ & $\begin{array}{r}120(88.9) \\
15(11.1)\end{array}$ & 0.346 \\
\hline $\begin{array}{l}\text { Target body core temperature } \\
\text { Same with } \mathrm{RCTs}^{\mathrm{c}} \\
\text { Difference } \leq 0.5^{\circ} \mathrm{C} \\
\text { Difference }>0.5^{\circ} \mathrm{C}\end{array}$ & $\begin{array}{c}7(7.9) \\
70(13.5) \\
12(13.5)\end{array}$ & $\begin{array}{l}41(30.4) \\
91(2.2) \\
3(2.2)\end{array}$ & $<0.001$ \\
\hline $\begin{array}{l}\text { Use of aEEG } \\
\text { Yes } \\
\text { No }\end{array}$ & $\begin{array}{l}15(16.9) \\
74(83.1)\end{array}$ & $\begin{array}{l}89(67.4) \\
43(32.6)\end{array}$ & $<0.001$ \\
\hline $\begin{array}{l}\text { Neuroimaging studies performed routir } \\
\text { MRI } \\
\text { CT scan }\end{array}$ & $\begin{array}{l}81(91.0) \\
33(37.1)\end{array}$ & $\begin{array}{r}131(97.0) \\
23(17.0)\end{array}$ & $\begin{array}{l}0.147 \\
0.003\end{array}$ \\
\hline $\begin{array}{l}\text { Cooling duration } \\
72 \text { hours } \\
\text { Other durations }\end{array}$ & $\begin{array}{l}63(76.8) \\
19(23.2)\end{array}$ & $\begin{array}{r}126(95.5) \\
6(4.5)\end{array}$ & $<0.001$ \\
\hline $\begin{array}{l}\text { Rate of rewarming } \\
\leq 0.5^{\circ} \mathrm{C} / \text { hour } \\
\leq 1^{\circ} \mathrm{C} / \text { day or slower }\end{array}$ & $\begin{array}{l}20(23.0) \\
67(77.0)\end{array}$ & $\begin{array}{l}96(73.3) \\
35(26.7)\end{array}$ & $<0.001$ \\
\hline $\begin{array}{l}\text { Routine use of muscle relaxant } \\
\text { Yes } \\
\text { No }\end{array}$ & $\begin{array}{l}16(19.0) \\
68(81.0)\end{array}$ & $\begin{aligned} 5 & (3.8) \\
127 & (96.2)\end{aligned}$ & 0.001 \\
\hline $\begin{array}{l}\text { Minimum follow-up duration of infant } \\
\text { Up to } 3 \text { years } \\
\text { 3-6 years } \\
\text { Longer than } 6 \text { years }\end{array}$ & $\begin{aligned} 58 & (67.4) \\
21 & (24.4) \\
7 & (8.1)\end{aligned}$ & $\begin{array}{l}84(65.6) \\
34(26.6) \\
10(7.8)\end{array}$ & 0.940 \\
\hline $\begin{array}{l}\text { Assessment of neurodevelopmental ou } \\
\text { Available } \\
\text { Not available }\end{array}$ & $\begin{array}{l}\text { ndividualized b } \\
\quad 71(88.8) \\
9(11.3)\end{array}$ & $\begin{array}{r}114(84.4) \\
21(15.6)\end{array}$ & 0.679 \\
\hline
\end{tabular}

Values are shown as number $(\%)$, unless otherwise stated.

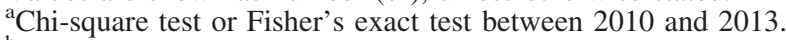

${ }^{b}$ Electronic, servo-controlled cooling devices approved by the Japanese Ministry of Health, Labour, and Welfare for the purpose of therapeutic hypothermia.

c34.5 (selective head cooling) or 33.5 (whole body cooling) $-0.5 \mathrm{C}$.

aEEG, amplitude-integrated EEG; RCT, randomized-controlled trial.

Recently, a group of five regional centers reported improved quality of TH using standard quality control methodology, which addressed timely identification and referral of newborn infants to cooling centers, implementation of standard cooling and monitoring protocols, assessment of the clinical condition and outcome using biomarkers and standardized neurodevelopmental follow up, and enrolment of infants in a national registry (Olsen et al., 2013). These findings, along with our experience, highlight the importance of a systematic approach for improving the quality of practice using persistent education and sustained multidisciplinary leadership.

In our current project, we conducted a set of surveys involving most registered level-II/III neonatal intensive care centers in Japan, which demonstrated significant changes in practice before and after our interventions. However, we were unable to evaluate the direct impact of our program, because it targeted the entire nation. Therefore, the drastic 
change in practice observed in more than 200 level-II/III centers might, at least in part, be due to other factors, such as the publication of systematic reviews and 2010 CoSTR itself (Edwards et al., 2010; Perlman et al., 2010; Jacobs et al., 2013).

Several other factors, which are specific to the system of neonatal medicine in Japan, may have to be highlighted before translating our findings into clinical practice in other parts of the world. Neonatal intensive care centers in Japan are generally small with less than 15 intensive cots. Most of these provide tertiary care with a relatively small number of staff (Kusuda et al., 2006), where clinical protocols are more likely to be abbreviated. However, empirical modification of standard therapy also occurs in other developed countries (Azzopardi et al., 2012; Olsen et al., 2013). Careful and persistent assessments are required to compare practice in different countries. This could be achieved by comparing adherence to the standard protocol between registries conducted in another country (e.g., the United Kingdom) and Japan.

\section{Conclusions}

We observed a rapid and drastic improvement in adherence to standard cooling protocols following the update of international guidelines on resuscitation and the integration of nationwide implementation programs in Japan. International consensus guidelines coupled with domestic strategic action plans, including the formulation of clinical recommendations, training of medical staff, and facilitation of a national case registry, might be effective in changing empirical approaches to evidence-based medical practice. Sustained educational programs, intermittent assessment of practice, and facilitation of a long-term follow-up system with appropriate assessment tools of neurodevelopmental outcomes are required.

\section{Acknowledgments}

The authors are grateful to the participants of the two nationwide surveys and to the expert committee members for their rigorous contributions. This work was supported by the Japanese Ministry of Health, Labour, and Welfare (Clinical and Practical Research on the Japanese Guideline of Neonatal Cardio-Pulmonary Resuscitation Based on Consensus 2010; Health and Labour Sciences Research Grants, Comprehensive Research on Life-Style Related Diseases, including Cardiovascular Diseases and Diabetes Mellitus). Dr. O. Iwata was funded by the Japan Science and Technology Agency and the Ministry of Education, Culture, Sports, Science, and Technology (Grant in Aid for Scientific Research B01-24119004, Constructive Developmental Science, Innovative Areas). Dr. T. Takenouchi was funded by Kawano Masanori Memorial Public Interest Incorporated Foundation for Promotion of Pediatrics and Japan Society for the Promotion of Science (Grant in Aid for Scientific Research 24791121). Dr. S. Iwata was funded by the Japan Science and Technology Agency and the Ministry of Education, Culture, Sports, Science, and Technology (Grant in Aid for Scientific Research C24591533). The funding organization had no role in the design and conduct of the study; collection, management, analysis, and interpretation of the data; preparation, review, or approval of this article; and decision to submit the article for publication. The funding sources that indirectly supported the authors did not have any role in the study design, collection, analysis, interpretation of data, writing of the report, and the decision to submit the paper for publication.

\section{Disclosure Statement}

The authors declare no conflicts of interest.

\section{References}

Azzopardi D, Strohm B, Linsell L, Hobson A, Juszczak E, Kurinczuk JJ, Brocklehurst P, Edwards AD. Implementation and conduct of therapeutic hypothermia for perinatal asphyxial encephalopathy in the UK-analysis of national data. PLoS One 2012;7:e38504.

Azzopardi D, Strohm B, Marlow N, Brocklehurst P, Deierl A, Eddama O, Goodwin J, Halliday HL, Juszczak E, Kapellou O, Levene M, Linsell L, Omar O, Thoresen M, Tusor N, Whitelaw A, Edwards AD. Effects of hypothermia for perinatal asphyxia on childhood outcomes. $N$ Engl J Med 2014;371:140-149.

Azzopardi DV, Strohm B, Edwards AD, Dyet L, Halliday HL, Juszczak E, Kapellou O, Levene M, Marlow N, Porter E, Thoresen M, Whitelaw A, Brocklehurst P. Moderate hypothermia to treat perinatal asphyxial encephalopathy. N Engl J Med 2009;361:1349-1358.

Edwards AD, Brocklehurst P, Gunn AJ, Halliday H, Juszczak E, Levene M, Strohm B, Thoresen M, Whitelaw A, Azzopardi D. Neurological outcomes at 18 months of age after moderate hypothermia for perinatal hypoxic ischaemic encephalopathy: synthesis and meta-analysis of trial data. BMJ 2010; 340:c363.

Gluckman PD, Wyatt JS, Azzopardi D, Ballard R, Edwards AD, Ferriero DM, Polin RA, Robertson CM, Thoresen M, Whitelaw A, Gunn AJ. Selective head cooling with mild systemic hypothermia after neonatal encephalopathy: multicentre randomised trial. Lancet 2005;365:663-670.

Guillet R, Edwards AD, Thoresen M, Ferriero DM, Gluckman PD, Whitelaw A, Gunn AJ. Seven- to eight-year follow-up of the CoolCap trial of head cooling for neonatal encephalopathy. Pediatr Res 2012;71:205-209.

Iwata O, Nabetani M, Takenouchi T, Iwaibara T, Iwata S, Tamura M. Hypothermia for neonatal encephalopathy: Nationwide Survey of Clinical Practice in Japan as of August 2010. Acta Paediatr 2012;101:e197-e202.

Iwata $\mathrm{O}$, Takenouchi T. Past, present and future of hypothermic neuroprotection for neonatal encephalopathy in Japan: time to say good-by to the old remedies. Brain Dev 2012;34:163-164.

Iwata S, Iwata O, Olson L, Kapetanakis A, Kato T, Evans S, Araki Y, Kakuma T, Matsuishi T, Setterwall F, Lagercrantz H, Robertson NJ. Therapeutic hypothermia can be induced and maintained using either commercial water bottles or a "phase changing material" mattress in a newborn piglet model. Arch Dis Child 2009;94:387-391.

Jacobs SE, Berg M, Hunt R, Tarnow-Mordi WO, Inder TE, Davis PG. Cooling for newborns with hypoxic ischaemic encephalopathy. Cochrane Database Syst Rev 2013;1: CD003311.

Japan Society of Perinatal and Neonatal Medicine. www.jspnm .com/Eng/default.aspx, accessed on September 18, 2014.

Kendall GS, Kapetanakis A, Ratnavel N, Azzopardi D, Robertson NJ. Passive cooling for initiation of therapeutic hypothermia in neonatal encephalopathy. Arch Dis Child Fetal Neonatal Ed 2010;95:F408-F412. 
Kusuda S, Fujimura M, Sakuma I, Aotani H, Kabe K, Itani Y, Ichiba H, Matsunami K, Nishida H. Morbidity and mortality of infants with very low birth weight in Japan: center variation. Pediatrics 2006;118:e1130-e1138.

Laventhal NT, Barks JD, Kim SY. Off-label use of therapeutic hypothermia for infants with hypoxic-ischemic encephalopathy. Virtual Mentor 2012;14:784-791.

Neonatal Hypothermia Task Force Japan. Official Website for the Baby Cooling Japan Registry. www.babycoolingjp/, 2012, accessed on September 18, 2014.

Olsen SL, Dejonge M, Kline A, Liptsen E, Song D, Anderson B, Mathur A. Optimizing therapeutic hypothermia for neonatal encephalopathy. Pediatrics 2013;131:e591-e603.

Perlman JM, Wyllie J, Kattwinkel J, Atkins DL, Chameides L, Goldsmith JP, Guinsburg R, Hazinski MF, Morley C, Richmond S, Simon WM, Singhal N, Szyld E, Tamura M, Velaphi S. Part 11: neonatal resuscitation: 2010 International Consensus on Cardiopulmonary Resuscitation and Emergency Cardiovascular Care Science With Treatment Recommendations. Circulation 2010;122:S516-S538.

Robertson NJ, Nakakeeto M, Hagmann C, Cowan FM, Acolet D, Iwata O, Allen E, Elbourne D, Costello A, Jacobs I. Therapeutic hypothermia for birth asphyxia in low-resource settings: a pilot randomised controlled trial. Lancet 2008;372:801-803.

Shankaran S. Hypoxic-ischemic encephalopathy and novel strategies for neuroprotection. Clin Perinatol 2012;39:919-929.

Shankaran S, Laptook AR, Ehrenkranz RA, Tyson JE, McDonald SA, Donovan EF, Fanaroff AA, Poole WK, Wright LL, Higgins RD, Finer NN, Carlo WA, Duara S, Oh W, Cotten CM, Stevenson DK, Stoll BJ, Lemons JA, Guillet R, Jobe AH. Whole-body hypothermia for neonates with hypoxic-ischemic encephalopathy. N Engl J Med 2005;353:1574-1584.

Shankaran S, Pappas A, McDonald SA, Vohr BR, Hintz SR, Yolton K, Gustafson KE, et al. Childhood outcomes after hypothermia for neonatal encephalopathy. N Engl J Med 2012;366:2085-2092.

Takenouchi T, Iwata O, Nabetani M, Tamura M. Therapeutic hypothermia for neonatal encephalopathy: JSPNM \& MHLW Japan Working Group Practice Guidelines Consensus Statement from the Working Group on Therapeutic Hypothermia for Neonatal Encephalopathy, Ministry of Health, Labour and Welfare (MHLW), Japan, and Japan Society for Perinatal and Neonatal Medicine (JSPNM). Brain Dev 2012;34:165-170.

Tamura M. Practical Textbook of Neonatal Resuscitation Based on 2010 Japanese Guidelines for Resuscitation. Medical View, Tokyo: Tokyo Igaku-sha, 2010.

Tamura M, Iwata O, Iwata S, Nabetani M, Takenouchi T. Practical Textbook of Evidence-Based Therapeutic Hypothermia for Newborn Infants. Tokyo: Tokyo Igaku-Sha, 2010.

Thayyil S, Costello A, Shankaran S, Robertson NJ. Therapeutic hypothermia for neonatal encephalopathy implications for neonatal units in India. Indian Pediatr 2009;46:283-289.

Thoresen M. Patient selection and prognostication with hypothermia treatment. Semin Fetal Neonatal Med 2010;15:247252.

Address correspondence to: Osuke Iwata, MD, PhD Department of Pediatrics \& Child Health Centre for Developmental \& Cognitive Neuroscience Kurume University School of Medicine 67 Asahimachi

Kurume

Fukuoka 830-0011

Japan

E-mail: o.iwata@ucl.ac.uk 